\section{Normal tissue complications after radiation therapy}

\author{
Jolyon H. Hendry, ${ }^{1}$ \\ Branislav Jeremić, ${ }^{1}$ \\ and Eduardo H. Zubizarreta ${ }^{1,2}$
}

Suggested citation: Hendry JH, Jeremić B, Zubizarreta EH. Normal tissue complications after radiation therapy. Rev Panam Salud Publica. 2006; 20(2/3):151-60.

Key words: neoplasms; radiotherapy; dose-response relationship, radiation; radiation injuries.

\footnotetext{
1 International Atomic Energy Agency, Division of Human Health, Applied Radiobiology and Radiotherapy Section, Vienna, Austria. Send correspondence to: Dr. Jolyon H. Hendry, Applied Radiation Biology and Radiotherapy Section, Division of Human Health, International Atomic Energy Agency, Wagramer Strasse 5, P.O. Box 100, A-1400 Vienna, Austria. E-mail: j.hendry@iaea.org

2 Hospital Pereira Rossell, Instituto de Radiología y Centro de Lucha Contra el Cáncer, Montevideo, Uruguay.
}

\section{SYNOPSIS}

This paper describes the biological mechanisms of normal tissue reactions after radiation therapy, with reference to conventional treatments, new treatments, and treatments in developing countries. It also describes biological reasons for the latency period before tissue complications arise, the relationship of dose to incidence, the effect of increasing the size of the irradiated volume, early and late tissue reactions, effects of changes in dose fractionation and dose rate, and combined chemotherapy and radiotherapy responses. Examples are given of increases in knowledge of clinical radiobiology from trials of new protocols. Potential modification to treatments include the use of biological response modifiers. The introduction of "response prediction" modifications to treatments might also be available in the near future. Finally, the paper points out that in some radiotherapy centers, the biologically-effective doses prescribed for combined brachytherapy and teletherapy treatment of cervix cancer are lower than those prescribed in other centers. This issue needs to be addressed further. The wealth of preclinical and clinical data has led to a much greater understanding of the biological basis to radiotherapy. This understanding has underpinned a variety of new approaches in radiotherapy, including both physical and biological strategies. There is also the important issue of treatment of a large number of cancers in developing countries, for which efficacious resourcesparing protocols are being continuously developed. A unified scoring system should be widely accepted as the new standard in reporting the adverse effects of radiation therapy. Likewise, late toxicity should be reported on an actuarial basis as a mandatory endpoint.

Radiation therapy has been used for over 100 years. It is a proven method for controlling malignancies and for prolonging the life of individuals who would otherwise die from their cancer. Radiation therapy is used in somewhat more than half of all cancer treatments, and in some cases it is the preferred and most effective treatment of all. In other cases, it is used in combination with chemotherapy or surgery.

Despite their benefits, all treatments against diseases are associated with side effects to some degree. Cytotoxic treatments against cancer, including radiation therapy, cause injury to normal tissues, which ultimately limits the dose that determines the likelihood of cure.

When cancers are irradiated, some normal tissue is also irradiated, and this causes injury that gives rise to tissue reactions. In many cases, these reactions are minor and transient, but in a few cases 
they can be prolonged and more severe. The reactions of greatest concern are those that appear months or years after therapy, making them more difficult to treat. Severe reactions in a small number of patients impose a limit on the dose that can be delivered, not just to them individually but to any patient. Physical and biological strategies are being devised to increase this limit in order to be able to deliver a higher dose in an attempt to control more cancers (tumors). One physical strategy is to reduce the irradiated volume as much as possible, so that the smaller volume can tolerate higher doses. Another strategy is to use very small dose fractions in order to exploit the greater fractionation sensitivity of late-reacting normal tissues than of tumors, so that higher tolerable doses can be accumulated resulting in more cured tumors. Three examples of biological strategies are: (1) making the radiation more effective in killing tumor cells through the utilization of the latest generation of molecular-pathway-based radiosensitizers; (2) predicting which patients will react the most, thus allowing for the remainder to be given a higher dose; and (3) applying selective targeting of radiation to the tumor cells.

\section{MECHANISMS OF TISSUE REACTIONS}

Advances in radiation technology and in radiation dose-fractionation delivery patterns, as well as the use of additional therapies, have altered the pattern of side effects (1). Historically, early skin reactions were generally dose-limiting due to the depth dose profile for orthovoltage radiotherapy. Although emphasis is still being placed on acute toxicity, today much of the focus has shifted toward late effects. Less aggressive radiotherapy protocols generally succeed in preventing severe morphological and structural changes such as fistulae and chronic ulcerations. However, irradiation may result in chronic changes in the functioning of organs such as the heart, lung, or kidney, that may become clinically manifest several years after treatment. This picture may change again with the recent advances and expected innovations in radiation and cancer biology, in functional imaging, and in radiation therapy planning and delivery. All these improvements tend to lead to an intensification of locoregional treatment.

Early tissue reactions, such as inflammation, occur within hours to several weeks after therapy due to changes in cell membrane permeability and histamine release. Subsequent early tissue reactions occur as a consequence of cell loss, causing mucositis and epidermal desquamation.

Early tissue reactions that are a result of cell loss are a feature of renewing tissues, such as bone marrow, epidermis, and mucosa. These tissues fol- low a hierarchical proliferative organization in which stem cells and daughter precursor cells with the ability to divide and differentiate give rise to cells which mature to form the functional end cells in tissues (2).

The sterilization of some or all of the stem and precursor cells in tissues results in early desquamatory reactions in epithelia, as well as hemopoietic depression. Such consequences ultimately result in a transitory or permanent decrease in the production of mature cells, depending on the radiation dosage level. The time course of the expression and restoration of tissue components generally depends on their normal (unirradiated) rate of renewal, and it is dosedependent after low doses. After high doses, complete denudation of such tissues occurs at a time equivalent to the lifetime of new mature cells, including cells produced by any radioresistant precursor cells. This pattern of response has been well described for many types of renewal tissues $(3,4)$.

On the other hand, late tissue and organ reactions are a consequence of cellular damage and injury to a complex network of interacting populations of cells (5). Such interacting populations of cells include relatively resistant parenchymal cells, which are mainly non-dividing. However, these cells can initiate division as a consequence of slow cell depletion due to radiation-induced abortive divisions. These populations of parenchymal cells, such as those in the liver and kidney, are capable of function as well as induced multiplication. They have been called flexible populations (3), in contrast to the hierarchical populations in renewing tissues.

\section{LATENCIES}

In the case of hierarchical tissues, i.e. tissues which have a hierarchical proliferative organization, the latency period prior to the gross expression of injury is directly related to the turnover (renewal) time of the tissue. Therefore, the latency period is short for intestinal reactions because the intestinal (mucosal) tissues have a high turnover rate. The opposite can be said for skin desquamation, which has a much longer latency period. After low radiation doses there is a dose-dependent latency due to the decreasing proportion of precursor cells undergoing successful cell division (6). At high doses there is a plateau in the timing of the response, when all cells are sterilized, no matter how high the dose. In the case of slowly-proliferating flexible cell populations, there is a characteristic longer, more intense and dose-dependent latency period before expression of damage. Detailed studies on telangiectasia provide a very clear example of this effect (7). Also, there is an increasing incidence 
of injury with increasing doses before the plateau in timing occurs at a very high dose (3).

From both a biological and clinical standpoint, it is useful to roughly classify normal tissue effects into early effects and late effects. Early effects are expressed during or immediately after the end of therapy; late effects may become manifest after symptom-free latency periods of months to years. Indeed, there is documented evidence that late effects continue to increase for over a decade in surviving individuals (8).

There is no consensus in the literature concerning the exact definition of "early effect" and of "late effect." Often an operational definition is used, and effects are classified based on an arbitrary cutoff for their latency period. One cutoff that has been used is 90 days after the onset of the treatment. However, it has also been proposed that late effects be defined as those that occur or that have not healed by at least 90 days after the end of therapy (9).

\section{REACTION SCORING SCALES}

There is a fairly comprehensive literature on early morbidity after both radiotherapy and chemotherapy. This has resulted in the development and implementation of comprehensive scoring systems designed for radiotherapy (such as the RTOG/ EORTC (Radiation Therapy Oncology Group/ European Organisation for Research and Treatment of Cancer) system) and for chemotherapy (such as the Eastern Cooperative Oncology Group Common Toxicity Criteria (CTC) or the World Health Organization system). These have been amalgamated into CTC version 2.0 (10), which is aimed at a common system that can apply to either radiotherapy or chemotherapy, individually or in combination. Recently, a more comprehensive version of the CTC criteria (CTCAE v. 3.0) addressed an increased need for more precise reporting of adverse events (11). These different systems have been used in a variety of clinical studies as well as in routine clinical practice.

Toxicity criteria for late effects are much less established than those for early effects (1). The RTOG/EORTC Late Radiation Morbidity Scoring Schema is widely used in multi-center trials in Europe and the United States of America. It is rather simple and easy to use, and it is the system usually found in the scientific literature. The most ambitious attempt so far to develop a comprehensive system for the grading and recording of late radiation effects was the "scoring system of late effects on normal tissues," or the SOMA/LENT scale (12). (SOMA is an abbreviation for "subjective symptoms, objective signs, management, and analytical measures." LENT is an abbreviation for "late effects on normal tissues.") The characteristic feature of the SOMA/LENT system is that each toxicity item is classified as subjective, objective, management-related, or analytical. In the original publication of the SOMA/LENT system, it was suggested that each individual item's score for an organ be added in order to then calculate the average score. This is clearly not a very sound system. In the case of lung reactions, for example, it was proposed to add the eight items in the SOMA part of the scale and then divide by eight. Thus, a patient dying (grade 5 per definition) from restricted pulmonary function without having developed any of the other seven signs or symptoms, or having management interventions for pulmonary injury, would get a score of $5 / 8$, or 0.625 . This value is less than that for a patient who has grade 1 signs and symptoms for all the items. One obvious idea is to record the maximum grade of any toxicity item for a specific organ or tissue and use this as the grade of toxicity (13). Thus, a patient experiencing, say, a grade 3 loss of sphincter control after radiotherapy will be recorded as having experienced a grade 3 rectal complication. This suggestion still involves a number of assumptions regarding the comparability of grades across toxicity items. From a biological perspective, it seems illogical to even attempt to pool various components of morbidity and arrive at a single number that quantifies late effects (14).

\section{DOSE-RESPONSE CURVES}

Tissue and organ reactions vary with the dose, in both severity and incidence. In general, the doseincidence relationship will be sigmoid in shape (S-shaped) when plotted on linear axes, with the effect becoming more frequent as the dose increases. The steepness of the curve is governed largely by the degree of variation in sensitivity among the patients.

The severity of the pathological condition increases most markedly in those individuals in a subgroup who are most sensitive (Curve a in the lower panel of Figure 1), reaching the threshold of detectability at a lower dose than in the less sensitive groups (Curve b, Curve c, and Curve d in Figure 1). The dose range over which the different subgroups cross the same morbidity threshold is reflected in the upper panel of Figure 1, which shows the frequency of morbidity in the total population. That frequency reaches $100 \%$ only at the dose that is sufficient to exceed the defined threshold in all members of the population.

There are many reported examples of the steepness of dose-incidence curves for morbidity in particular tissues and organs in series of radiotherapy patients who are receiving different doses. One way to 
FIGURE 1. How the incidence ("frequency" in the upper panel) of a reaction or clinically recognizable pathological condition increases as a function of dose ("dose" in the upper panel) in a population of individuals of varying sensitivities, and what the dose-severity relationship is for the component subpopulations of individuals with various sensitivities (lower panel)

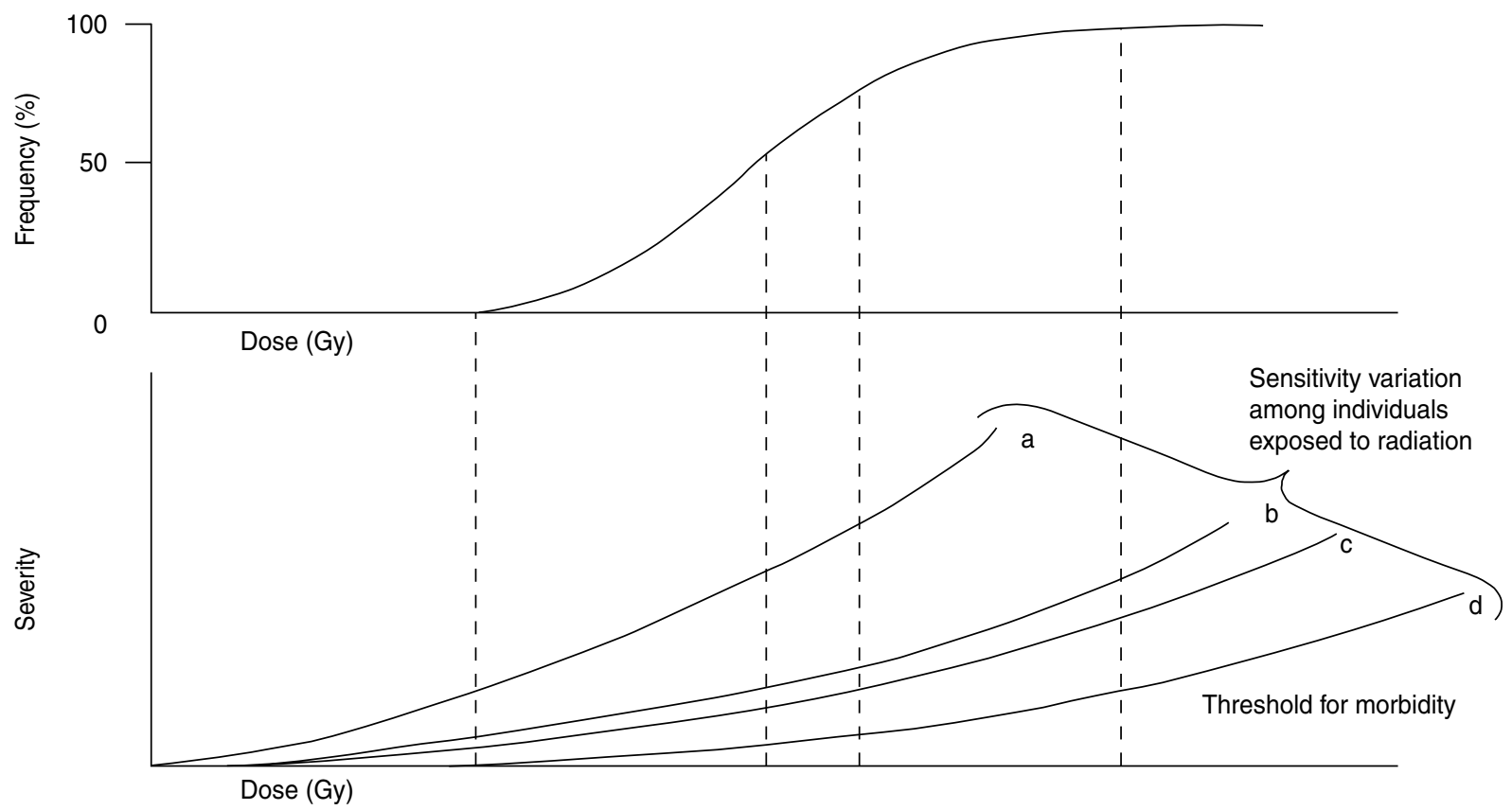

describe the steepness is the absolute percentage increase in the incidence of morbidity among a population of patients when the dose is increased by $1 \%$. Examples of this measure of steepness for different tissues in different series of patients, calculated on a common basis of 2 Gy per fraction and at the steepest part of the curve (the midpoint, of $50 \%$ incidence), are available (15). There is a wide variation in steepness due largely to the heterogeneity in the particular patient population used. However, it should be noted that, in general, the dose-incidence curves for morbidity are steeper than they are for tumor control. This indicates that there is even greater variation among patients in the response of a tumor than in the response of normal tissue.

\section{VOLUME EFFECTS}

In general, tissue reactions are greater when greater volumes are irradiated. This effect is most marked for very small volumes because the migration of cells from the edges of radiation fields affects healing in smaller volumes much more than in larger ones. For larger irradiated volumes, which are the ones most common in radiotherapy, the volume effect is less marked but still important. The presence of a volume effect is the rationale for new strategies to reduce irradiated volumes. These include dynamic imaging (used to reduce irradiated tumor margins), intensity-modulated radiotherapy (used to shape the irradiated fields more closely around the tumor), and protons (which can be used to provide a sharper edge to the irradiated volume than is possible with $X$ rays, gamma rays, or electrons).

For skin, the tolerance of a larger irradiated region may be reduced compared to that of a smaller irradiated region, although the reaction level may be little increased. This is because the likelihood of any area within the irradiated region not healing properly increases with an increase in the number of such irradiated areas. Also, the architecture of organ systems has an influence on the volume effect. Some organ systems are comprised of functional tissue subunits arranged in parallel, such as nephrons in the kidney and alveoli in the lung. In these cases, parts of the organ can be irradiated and injured with no functional defects because the other regions can compensate. In contrast, organs or tissues comprised of functional components in a serial arrangement, such as the spinal cord, intestine, and blood vessels, can be functionally damaged to irreparable levels by injury in one small region (16).

\section{GENERIC AND CONSEQUENTIAL LATE REACTIONS}

In recent years it has become clear that late reactions in tissues and organs can be caused primar- 
ily in two ways. One is through direct injury to the responsible tissues, for example, the vasculature (causing, for instance, ischemia) or stroma (fibrosis). These injuries are referred to as generic late reactions. The other is through early injury to overlying protective tissues, such as mucosa or epidermis, causing later injury in the underlying tissues. These are referred to as consequential late reactions.

Unconventional, more aggressive irradiation protocols are usually associated with an aggravation of acute reactions. Overexposures of patients, which happen occasionally, can have this same effect. Thus, aggressive irradiation protocols and the incidence of overexposure to radiation predominantly generate consequential late reactions. Such consequential late reactions are found in organ systems where the acute response is associated with an impairment of the tissue barrier against mechanical or chemical stress (17). Hence, the reactions are found mainly in the urinary and intestinal tracts, in mucosa anywhere, and to some extent in skin. The presence of consequential reactions can often confound the interpretation of late reactions when unconventional radiation protocols are used. Also, the prediction of reaction levels may be inaccurate when new schedules are trialed $(18,19)$. In addition, amelioration of the acute response to irradiation may be a useful approach to minimize some of the consequential late side effects of curative radiotherapy.

\section{FRACTIONATION AND DOSE-RATE EFFECTS}

The benefit of hyperfractionated treatments (using lower doses per fraction than are given with a normal schedule, and giving more treatments per day) is now well established (20). However, this has not yet led to wider application of this strategy in clinical practice. This technique prevents generic late reactions. Generic late reactions have a high fractionation sensitivity, which is characterized by a low $\alpha / \beta$ ratio in the commonly-employed linear-quadratic formalism (20). (The $\alpha / \beta$ ratio is a measure of the fractionation sensitivity of a tissue). The technique also permits the delivery of a more biologically effective dose to the tumor, while keeping the level of complications acceptably low. One milestone in this strategy was the successful implementation of the continuous hyperfractionated and accelerated radiation therapy (CHART) regimen for lung cancer and for head and neck cancer, delivering the total treatment in 12 days, with three fractions of 1.5 Gy per day (21). Another milestone was the EORTC 22791 trial of pure hyperfractionation for head and neck cancer, using conventional treatment times (22). Unfortunately, these new schedules are labor-intensive for staff and often difficult to implement in conventional radiotherapy departments. Therefore, less-modified schedules are being sought as a compromise. A recent interesting development that reverses this trend toward using hyperfractionation has to do with prostate cancer. In this case, the slow-growing tumor responds as if it were more sensitive to dose fraction size than even late-reacting normal tissue. Trials are being conducted to test whether high doses per fraction and fewer fractions (hypofractionation), rather than low doses per fraction, are beneficial $(23,24)$.

Another aspect of fractionation is the duration of the schedule. Longer schedules are beneficial in allowing regeneration of early-reacting renewing tissues, and longer schedules also reduce any consequential late reactions. However, such schedules may allow tumor cell repopulation, which is detrimental to tumor cure. It is now well established that for head and neck cancers, repopulation of tumor clonogens starts after three to four weeks of treatment $(25,26)$. On the other hand, accelerated (shorter) treatments, which will be completed before tumor cell repopulation becomes important, can increase acute reactions and thus may increase consequential late reactions as well.

Fractionated doses should be delivered with an interval of at least six to eight hours between fractions, so that intracellular repair is virtually complete. Otherwise, the total dose must be reduced to avoid increasing morbidity (27). However, there are data showing that even shorter interfraction intervals in hyperfractionation regimens, alone or with concurrent chemotherapy (28), have led to more acute toxicity, but not to late toxicity (29). No difference was observed between shorter and longer intervals in terms of both acute and late toxicity (30). Finally, multivariate analyses with 536 patients confirmed that the interfraction interval was not a predictor of high-grade acute or late toxicity. Additionally, recent analysis in locally advanced, unresectable (stage III) non-small cell lung cancer showed that patients treated with hyperfractionated radiation therapy using shorter interfraction intervals (4.5-5.0 hours) fared even better than patients treated with longer intervals (5.5-6.0 hours) (29). Contrary to these findings, the Radiation Therapy Oncology Group (RTOG) (31) found more highgrade late toxicity in patients with upper respiratory and digestive tract cancers treated with hyperfractionation. Due to a lack of clinical investigations in other tumor sites, every caution should be exercised when hyperfractionated regimens are planned and carried out. Another aspect of this is repair occurring during delivery of a fraction (32). If cobalt-60 is the radiation source, as in many developing countries, and it has decayed so that the dose rate is 
FIGURE 2. Values of linear-quadratic equivalent dose (LQED) in Gy for cervical tumor dose prescriptions (solid squares and upper, solid line) and for calculated rectal doses (triangles and lower, dashed line) among 25 radiotherapy centers around the world

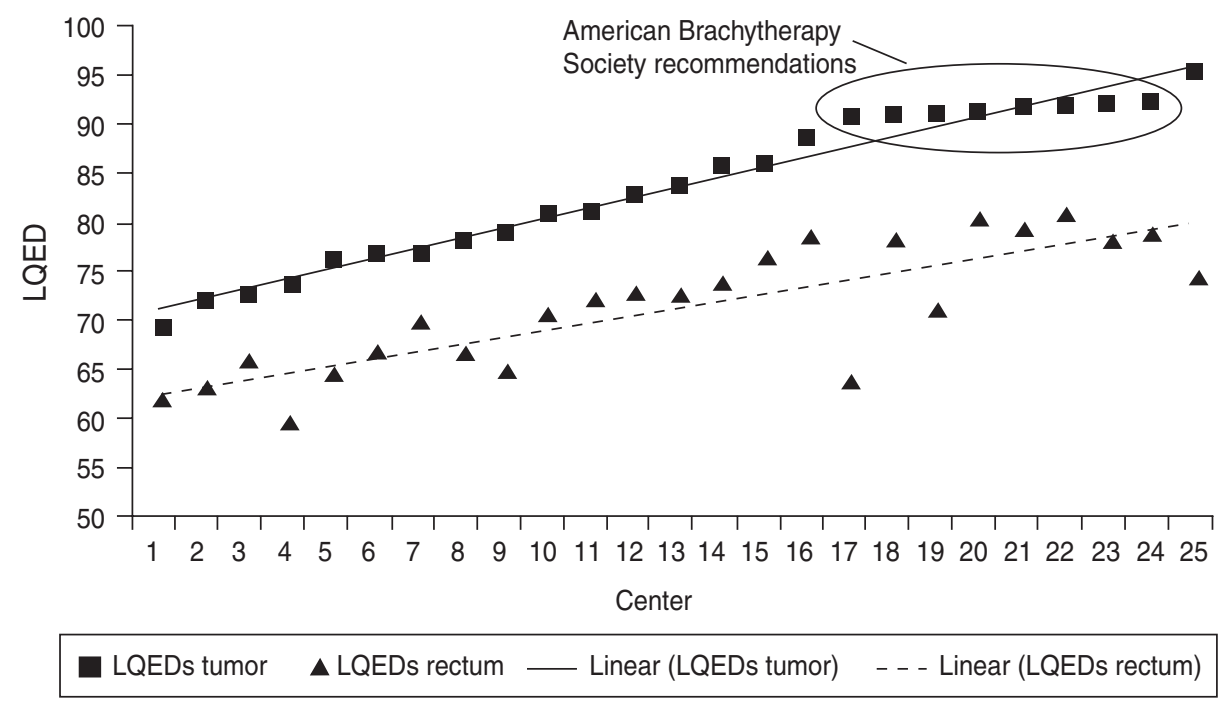

reduced, then the dose per fraction may need to be increased to compensate for the decreased effectiveness of the radiation. The same applies to more sophisticated technology, such as intensity-modulated radiation therapy (IMRT). With prolonged fraction delivery needed to execute sophisticated IMRT plans, a loss of biological effect may occur.

The influence of repair has been observed in numerous detailed studies using cell cultures or animal systems, particularly during irradiation at low dose rates (32). Brachytherapy treatments are one of the cornerstones of the treatment of cervical cancer, often in addition to external beam therapy (33). The brachytherapy is delivered using either lowdose-rate (LDR) irradiation (between 0.5 and $1.5 \mathrm{~Gy}$ per hour) in two sessions or, increasingly more commonly, several high-dose-rate (HDR) sessions ( 100 cGy per minute). The total dose is adjusted accordingly to give the same acceptable low level of morbidity, which is predominantly rectal injury. HDR is not better than LDR for these treatments (34), but it gives an acceptable result, and more patients can be treated with the equipment, although more staff resources are needed.

Around the world, LDR brachytherapy is being gradually replaced by HDR brachytherapy. Some randomized trials have shown that HDR can be as effective as LDR in terms of tumor control and late complications (35-37), but no formal trials have been performed to test different HDR schedules. The American Brachytherapy Society (ABS) published guidelines about dose and fractionation (38), based on a review of HDR schedules (39).
We have collated known dose prescriptions for cervical cancer used in 25 radiotherapy centers around the world. These dose prescriptions were converted to values of linear-quadratic equivalent dose (LQED) for the dose to the tumor (by convention, quoted at point $\mathrm{A}$ ) and the lower dose received by the rectum (assuming 70\% of the point $\mathrm{A}$ dose in the rectal wall). The conversion was done by calculation, using the LQ formalism and the following parameter values: $\alpha / \beta$ for tumor $=10 \mathrm{~Gy}$, half time of repair $=1.5$ hours; $\alpha / \beta$ for rectum $=3 \mathrm{~Gy}$, half time of repair $=1.5$ hours. The 25 values of tumor LQED were placed in ascending numerical order from the lowest to the highest, and the tumor LQED values were then plotted in Figure 2 along with their corresponding values of LQED for the rectum. The prescriptions used a variety of high-dose-rate treatments (21 schedules) and low-dose-rate treatments (4 schedules), plus external beam therapy. Trend lines are shown for visual clarity, and the centers using the ABS-recommended dose prescriptions for cervical cancer are circled. When the dose prescriptions are compared in terms of LQED, there is up to $25 \%$ less dose prescribed in those centers on the left side of Figure 2 compared to the higher doses on the right (including the ABS values, which are circled). As there exists some fear about the risk of increased late effects with the use of high-dose fractions in high-dose-rate cervical brachytherapy, it is possible that some of these lower-LQED schedules have been designed with excessive prudence. Randomized trials will be needed to determine the schemes with the optimal dose and fractionation. 
There are few publications from developing countries reporting their results for radiotherapy outcome in cervical cancer patients. Negative results or poor outcomes are not published as often as positive or good results. That could be a reason for the paucity of such publications. Moreover, followups are difficult and usually deficient, which makes it impossible to know the real situation. For example, in one study (40), with 16 patients with stage I cervical cancer, only 9 of them (56\%) showed tumor control and no complications after radiotherapy. This is a lower rate of tumor control than would be expected from other published series. Such a low rate might be attributed to long overall treatment time, setup or field-margin factors, or low total biologically effective doses (40).

\section{TRIALS AND ACCIDENTS}

As mentioned above, many radiotherapy trials have been undertaken to test hypotheses about the potential benefits of modified schedules. The most successful of these trials have been based on prior knowledge and logical expectations, such as the Danish Head and Neck Cancer Study Group (DAHANCA) sequential series of trials on dose fractionation and chemoradiotherapy (41).

Other trials have been implemented because of safety legislation, and sometimes these have provided very illuminating results. One example is the use of LDR remote-controlled afterloading brachytherapy, which was introduced because of concern over the safety of staff. At the time, it was not appreciated clinically that patients' tissue reactions would be different from the reactions in normally-treated patients using the even lower dose rates produced by the manually-inserted radium sources that had been used for many years. When increasing the dose rate from approximately $50 \mathrm{cGy}$ per minute to approximately $150 \mathrm{cGy}$ per minute, a dose reduction of between $20 \%$ and $25 \%$ was required in order to achieve a similar low incidence of bowel and urinary morbidity (42-44). These results were consistent with findings in experimental systems as well as with clinical results for more-homogeneous interstitial irradiations. Also, for both tumor control and complications, a high $\alpha / \beta$ value and a short half-time for repair best fitted the data. This result suggested that consequential late reactions rather than generic late reactions may be responsible for the incidence of morbidity resulting from such treatments (42).

Trials such as this or CHART often provide data that give useful additional knowledge about one or more underlying parameters that govern normal tissue response. In addition, the results from cases that entail the rare overexposure of groups of patients to radiation can provide information to supplement this knowledge. For example, in a cohort of 56 cervical and prostate cancer patients in Panama, half of them received some doses per fraction approximately double those prescribed. Seventeen of the 28 overexposed patients died from 35 days to 21 months after treatment; 13 of the fatalities were caused by rectal complications (40). Survival was improved by performing colostomies. Using the doses that were actually delivered to these patients, it was possible to estimate the tolerance dose, and above this dose there were some deaths. Thus, although it is hoped that such accidents will never occur, the knowledge provided from these rare events can help strengthen the knowledge of the upper limit of the tolerable dose in conventional treatments.

\section{RESPONSE PREDICTION AND PROTECTION OF NORMAL TISSUES}

As noted above, dose-incidence curves for normal tissue injury are sigmoid in shape. The first $5 \%$ incidence is often considered a general upper limit to acceptability (except in special cases, such as paralysis, for which it is less than $1 \%$ ). Less than one-fifth of this small fraction is comprised of individuals with known syndromes that predispose them to being radiosensitive. Therefore, the dose that induces, for example, a $5 \%$ incidence is denoted the tolerance dose, and all patients with a given stage of a certain type of tumor would be prescribed that dose. This means that $95 \%$ of patients do not develop a severe reaction. Therefore, in theory, a higher dose could be administered to these less sensitive patients in order to provide more effective control of their tumors (45). In order to implement this strategy, it is necessary to perform an assay to predict which patients are in the $5 \%$ category and which patients are in the remaining, 95\% category. One of the problems is that there is a random statistical component to the likelihood of a particular individual placing in a given category. Analysis of the occurrence of telangiectasia of the skin in patients treated with bilateral mammary radiotherapy fields showed that as much as $90 \%$ (with $95 \%$ confidence limits of $65 \%$ and $100 \%$ ) of the variability in the radioresponsiveness in the right-sided field was explained by the radioresponsiveness in the left-sided field (46). Hence, the random statistical component was fairly small, at approximately $10 \%$ of the total variation. However, this is the only example in the literature where these components of variability have been determined, and the general applicability of this result needs to be addressed for other endpoints and other tissues. To predict the nonrandom compo- 
nent, many assays have been tested, from molecular to chromosomal and cellular ones, with varying degrees of success. None of them has proved sufficiently robust to allow implementation of this type of dose-prescription-variation strategy. The best assay-that is, the one with the highest positive predictive value, in this case $90 \%$ - has been the enzyme marker Transforming Growth Factor beta (TGF $\beta$ ), used to predict, in a high percentage of lung cancer patients, the progression of marked radiation-induced fibrosis $(47,48)$.

It is increasingly recognized that the radiation response of normal tissues can be modified through the use of various agents. This could provide a strategy for all patients if the modification were selective for normal tissues and not for tumor. However, if the financial resources available are limited, this treatment should be used first with radiosensitive patients, so that the largest possible number of people would benefit for a particular given expenditure of financial resources. Early reactions in irradiated renewing tissues can be alleviated by the application of radical scavengers, such as amifostine, before irradiation. A recent randomized comparative trial confirmed that amifostine can reduce the severity and incidence of acute esophageal, pulmonary, and hematological toxicity resulting from intensive concurrent chemoradiation used for nonsmall cell lung cancer (49). Importantly, amifostine had no apparent effect on the survival of these patients, suggesting that it does not have a tumorprotective effect. This finding implies that therapeutic benefits should be achievable for amifostinetreated patients, and this will be tested in further clinical trials. Early tissue reactions can also be alleviated by the application of factors, in particular growth factors, after irradiation (50). These include hemopoietic growth factors in the case of bone marrow, epithelial growth factors for mucosa and epithelium, and essential fatty acids (EFAs) for skin. The mechanism is either for growth factors to accelerate the repopulation and differentiation of precursor cells, or for growth factors to help decrease the vascular component of radiation-induced injury, in the case of EFAs (51). The decreased reactions indicate that up to double the radiation dose can be tolerated by oral mucosa in the presence of keratinocyte growth factor (52). These radioprotective effects may be very useful in accelerated treatments, where early reactions are often more severe than they are in conventional treatments.

Late reactions can also be modified (50) by various vascular-associated compounds such as EFAs in the skin (51) and angiotensin II enzyme inhibitors or receptor blockers in the kidney (53). These agents at least delay the onset of functional injury, and they may also reduce its incidence.
Hence, in principle, these agents might not only reduce late reactions, which are dose-limiting, but also allow for the possibility of some dose escalation. The latter, in turn, would ultimately increase tumor control rates.

\section{RESIDUAL INJURY AND RETREATMENT}

Following radiotherapy, there is a recovery of normal tissues in surviving patients, but usually not to pre-irradiation levels of tolerance. For example, skin cells may become more susceptible to mechanical trauma. Moreover, bone marrow may be compromised in terms of its stem cell content, making it more susceptible to subsequent cytotoxic agents. These results indicate that retreatment may be possible, but only through the use of lower doses. There are now many cases of recurrences treated with reasonable success. Many findings within experimental animal systems, particularly on the kidney and spinal cord, provide evidence for increasing tolerance to retreatment after the first course of irradiation (54).

\section{CONCLUSIONS}

A wealth of preclinical and clinical data has led to a much greater understanding of the mechanistic basis to radiotherapy. This understanding has underpinned a variety of new approaches in radiotherapy, including the use of both physical and biological tools that range from conformal/IMRT techniques to biological response modifiers of various types. Examples of such technically advanced approaches include the use of radiosensitizers, protectors, growth factors, and inhibitors of molecular signaling pathways.

In addition to new advances, there is also the important issue of the treatment of a large number of cancers in developing countries, where resources are often very limited. Resource-sparing protocols of hypofractionation are under development, as are designer treatments for special situations, such as the radiotherapy of cancer in radiosensitive AIDS patients.

From the clinical standpoint, recent decades have witnessed numerous clinical trials that slowly introduced first acute toxicity and then late toxicity as important endpoints in treatment outcome. The problem of the use of different scoring systems must be addressed, leading eventually to a unified scoring system that is widely accepted as the new standard in reporting the adverse effects of radiation therapy. Unfortunately, much of the work has focused on acute toxicity, as is understandable, 
since it directly influences treatment delivery. This influence sometimes leads to poor compliance and treatment interruption, which negatively affect the outcome (30). Late toxicity was largely overlooked in the past, possibly due to the lack of uniform criteria for reporting it. It is now well recognized that late toxicity must indeed be reported as a mandatory endpoint on an actuarial basis. This may result in requests for prolonged follow-up, which may additionally burden both follow-up procedures and health care systems. However, if these difficulties are overcome, the ultimate benefit will be improved overall treatment outcomes.

\section{SINOPSIS}

\section{Las complicaciones de la radioterapia en los tejidos sanos}

En este artículo se describen los mecanismos biológicos que intervienen en las reacciones provocadas por la radioterapia, tanto con tratamientos convencionales como con los más nuevos, y los aplicados en países en desarrollo. Asimismo, se describen las bases biológicas del período de latencia que precede a la aparición de las complicaciones tisulares; la relación entre la dosis de radiación y la incidencia de complicaciones; las consecuencias de aumentar el volumen irradiado; las reacciones ti- sulares tempranas y tardías; los efectos de cambios en el fraccionamiento de las dosis y en las tasas de dosis; y las reacciones observadas al aplicar una combinación de quimioterapia y radioterapia. Se ofrecen ejemplos de nuevos conocimientos en el campo de la radiobiología clínica que se han adquirido mediante ensayos con nuevos protocolos. Entre las posibles modificaciones de los tratamientos figura el uso de modificadores de la respuesta biológica; en el futuro próximo, podría contarse también con modificaciones de los tratamientos para poder "predecir la respuesta". Por último, las dosis cuya eficacia biológica está demostrada y que están prescritas para tratar el cáncer cervicouterino usando una combinación de braquiterapia y teleterapia son menores en algunos centros que en otros, como se explica en este trabajo. El asunto debe examinarse más a fondo. Una gran abundancia de datos de carácter preclínico y clínico ha permitido comprender mucho mejor las bases biológicas de la radioterapia, y ello a su vez ha llevado a una serie de innovaciones en este campo, tanto en forma de estrategias físicas como biológicas. También es importante prestar atención al tratamiento de una gran variedad de cánceres en países en desarrollo, para los cuales continuamente se elaboran protocolos terapéuticos eficaces orientados a ahorrar recursos. Debería adoptarse en todas partes un único sistema de puntuación para documentar los efectos nocivos de la radioterapia. Asimismo, la toxicidad tardía debería ser un parámetro clínico de valoración obligatoria y figurar en las estadísticas de los resultados del tratamiento.

Palabras clave: neoplasias, radioterapia, relación dosisrespuesta en la radiación, traumatismos por radiación.

\section{REFERENCES}

1. Bentzen SM, Dörr W, Anscher M, Denham JW, Hauer-Jensen M, Marks L, et al. Normal tissue effects: reporting and analysis. Semin Radiat Oncol. 2003; 13(3):189-202

2. Potten CS, ed. Stem cells: their identification and characterization. Edinburgh: Churchill-Livingstone; 1983.

3. Wheldon TE, Michalowski AS, Kirk J. The effect of irradiation on function in self-renewing normal tissues with differing proliferative organization. $\mathrm{Br} \mathrm{J}$ Radiol. 1982;55(658):759-66.

4. Potten CS, Hendry JH, eds. Cytotoxic insult to tissue: effects on cell lineages. Edinburgh: Churchill-Livingstone; 1983.

5. Rubin P, Finkelstein JN, Williams PC. Paradigm shifts in the radiation pathophysiology of late effects in normal tissues: molecular vs. classic concepts. In: Tobias JS, Thomas PRM, eds. Current radiation oncology. Vol. 3. London: Arnold; 1997. Pp. 1-26.

6. Mason KA, Withers HR, Davis CA. Dose dependent latency of fatal gastrointestinal and bone marrow syndromes. Int J Radiat Biol. 1989;55(1):1-5.

7. Turesson I. Individual variation and dose dependency in the progression rate of skin telangiectasia. Int J Radiat Oncol Biol Phys. 1990;19:1569-74.

8. Jung H, Beck-Bornholdt HP, Svoboda V. Quantification of late complications after radiation therapy. Radiother Oncol. 2001;61:233-46.

9. Bentzen SM, Overgaard J. Clinical manifestations of normal-tissue damage. In: Steel GG. Basic clinical radiobiology. London: Arnold; 1997. Pp. 87-97.

10. Trotti A, Byhardt R, Stetz J. Common toxicity criteria: version 2.0, an improved reference for grading the acute effects of cancer treatment: impact on radiotherapy. Int J Radiat Oncol Biol Phys. 2000;47:13-47.

11. Trotti A, Colevas AD, Setser A, Rusch V, Jaques D, Budach V, et al. CTCAE v3.0: development of a comprehensive grading system for the adverse effects of cancer treatment. Semin Radiat Oncol. 2003; 13:176-81.

12. Pavy JJ, Denekamp J, Letschert J, Littbrand B, Mornex F, Bernier J, et al. Late effects toxicity scoring: the SOMA scale. Radiother Oncol. 1995;35:11-5.

13. Anacak Y, Yalman D, Ozsaran Z. Late radiation effects to the rectum and bladder in gynecologic cancer patients: the comparison of LENT/SOMA and RTOG/ EORTC late-effects scoring systems. Int J Radiat Oncol Biol Phys. 2001;50:1107-12.

14. Field SB, Upton AC. Non-stochastic effects: compatibility with present ICRP recommendations. Int J Radiat Biol. 1985; 48:81-94.

15. Bentzen SM. Dose-response relationships in radiotherapy. In: Steel GG, ed. Basic clinical radiobiology. London: Arnold; 2002. Pp. 94-104.

16. Withers HR, Taylor JM, Maciejewski B. Treatment volume and tissue tolerance. Int J Radiat Oncol Biol Phys. 1988;14(4): 751-9.

17. Dorr W, Hendry JH. Consequential late effects in normal tissues. Radiother Oncol. 2001;61:223-31.

18. Kaanders JH, van der Kogel AJ, Ang KK. Altered fractionation: limited by mucosal reactions? Radiother Oncol. 1998;50:247-60.

19. Fowler JF, Harari P, Leborgne F, Leborgne J. Acute radiation reactions in oral and pharyngeal mucosa: tolerable levels in altered fractionation schedules. Radiother Oncol. 2003;69:161-8.

20. Stuschke M, Thames HD. Hyperfractionated radiotherapy of human tu- 
mours: overview of the randomized clinical trials. Int J Radiat Oncol Biol Phys. 1997;37(2):259-67.

21. Saunders M, Dische S, Barrett A, Harvey A, Griffiths G, Palmar M. Continuous, hyperfractionated, accelerated radiotherapy (CHART) versus conventional radiotherapy in non-small cell lung cancer: mature data from the randomised multicentre trial. CHART Steering Committee. Radiother Oncol. 1999;52(2): 137-48.

22. Horiot JC, Le Fur R, N'Guyen T, Chenal C, Schraub S, Alfonsi S, et al. Hyperfractionation versus conventional fractionation in oropharyngeal carcinoma: final analysis of a randomized trial of the EORTC cooperative group of radiotherapy. Radiother Oncol. 1992;25(4):231-41.

23. Brenner DJ, Martinez AA, Edmundson GK, Mitchell C, Thames HD, Armour EP. Direct evidence that prostate tumors show high sensitivity to fractionation (low $\alpha / \beta$ ratio), similar to late-responding normal tissue. Int J Radiat Oncol Biol Phys. 2002;52:6-13.

24. Livsey JE, Cowan RA, Wylie JP, Swindell R, Read G, Khoo VS, et al. Hypofractionated conformal radiotherapy in carcinoma of the prostate: five-year outcome analysis. Int J Radiat Oncol Biol Phys. 2003;57(5):1254-9.

25. Withers HR Taylor JM, Maciejewski B. The hazard of accelerated tumour clonogen repopulation during radiotherapy. Acta Oncol. 1988;27(2):131-46.

26. Roberts SA, Hendry JH. Time factors in larynx tumour radiotherapy: lag times and intertumour heterogeneity in clinical datasets from four centers. Int J Radiat Oncol Biol Phys. 1999;45(5):1247-57.

27. Bentzen SM, Saunders MI, Dische S. Repair half-times estimated from observations of treatment-related morbidity after CHART or conventional radiotherapy in head and neck cancer. Radiother Oncol. 1999;53:219-26.

28. Jeremić B, Shibamoto Y. Effect of interfraction interval in hyperfractionated radiotherapy with or without concurrent chemotherapy for stage III nonsmall cell lung cancer. Int J Radiat Oncol Biol Phys. 1996;34:303-8.

29. Jeremić B, Milicic M, Dagovic A, Aleksandrovic J, Milisavljevic S. Interfraction interval in patients with stage III nonsmall cell lung cancer treated with hyperfractionated radiation therapy with or without concurrent chemotherapy. Final results in 536 patients. Am J Clin Oncol. 2004;27(6):616-25.

30. Jeremić B, Shibamoto $Y$, Milicic B, Dagovic A, Nikolic N, Aleksandrovic J, et al. Impact of treatment interruptions due to toxicity on outcome of patients with early stage (I/II) non-small-cell lung cancer (NSCLC) treated with hyperfractionated radiation therapy (Hfx RT) alone. Lung Cancer. 2003;40:317-23.

31. Cox JD, Pajak TF, Marcial VA. ASTRO plenary: interfraction interval is a major determinant of late effects, with hyperfractionated radiation therapy of carcinomas of upper respiratory and digestive tracts: results from Radiation Therapy Oncology Group protocol 8313. Int J Radiat Oncol Biol Phys. 1991;20: 1191-5.

32. Fowler JF, Welsh JS, Howard SP. Loss of biological effect in prolonged fraction delivery. Int J Radiat Oncol Biol Phys. 2004;59:242-9.

33. Hall EJ, Brenner DJ. The dose-rate effect revisited: radiobiological considerations of importance in radiotherapy. Int $\mathrm{J} \mathrm{Ra}$ diat Oncol Biol Phys. 1991;21(6):1403-14.

34. Nori D, Dasari N, Allbright RM. Gynecologic brachytherapy I: proper incorporation of brachytherapy into the current multimodality management of carcinoma of the cervix. Semin Radiat Oncol. 2002;12:40-52.

35. Patel FD, Sharma SC, Negi PS, Ghoshal S, Gupta BD. Low dose rate vs. high dose rate brachytherapy in the treatment of carcinoma of the uterine cervix: a clinical trial. Int J Radiat Oncol Biol Phys. 1994;28(2):335-41.

36. El-Baradie $\mathrm{M}$, Inoue $\mathrm{T}$, Murayama $\mathrm{S}$, Tang JT, Yamazaki H, Fournier-Bidoz N. HDR and MDR intracavitary treatment for carcinoma of the uterine cervix. A prospective randomized study. Strahlenther Onkol. 1997;173(3):155-62.

37. Hareyama M, Sakata K, Oouchi A, Nagakura $\mathrm{H}$, Shido $\mathrm{M}$, Someya $\mathrm{M}$, et al. High-dose-rate versus low-dose-rate intracavitary therapy for carcinoma of the uterine cervix: a randomized trial. Cancer. 2002;94(1):117-24.

38. Nag S, Erickson B, Thomadsen B, Orton C, Demanes JD, Petereit D. The American Brachytherapy Society recommendations for high-dose-rate brachytherapy for carcinoma of the cervix. Int J Radiat Oncol Biol Phys. 2000;48(1): 201-11.

39. Petereit DG, Pearcey R. Literature analysis of high dose rate brachytherapy fractionation schedules in the treatment of cervical cancer: is there an optimal fractionation schedule? Int J Radiat Oncol Biol Phys. 1999;43(2):359-66.

40. Borrás C, Barés JP, Rudder D, Amer A, Millán F, Abuchaibe O. Clinical effects in a cohort of cancer patients overexposed during external beam pelvic radiotherapy. Int J Radiat Oncol Biol Phys. 2004;59(2):538-50

41. Overgaard J, Hansen HS, Specht L, Overgaard M, Grau C, Andersen E, et al. Five compared with six fractions per week of conventional radiotherapy of squamous-cell carcinoma of head and neck: DAHANCA 6 and 7 randomised controlled trial. Lancet. 2003;362(9388): 933-40.

42. Roberts SA, Hendry JH, Swindell R, Wilkinson JM, Hunter RD. Compensation for changes in dose-rate in radical lowdose-rate brachytherapy: a radiobiological analysis of a randomised clinical trial. Radiother Oncol. 2004;70(1): 63-74.
43. Leborgne $\mathrm{F}$, Fowler JF, Leborgne $\mathrm{JH}$ Zubizarreta E, Chappell R. Fractionation in medium dose rate brachytherapy of cancer of the cervix. Int J Radiat Oncol Biol Phys. 1996;35(5):907-14.

44. Leborgne $\mathrm{F}$, Fowler JF, Leborgne $\mathrm{JH}$ Zubizarreta E, Chappell R. Biologically effective doses in medium dose rate brachytherapy of cancer of the cervix. Radiat Oncol Investig. 1997;5(6):289-99.

45. Mackay RI, Hendry JH. The modelled benefits of individualizing radiotherapy patients' dose using cellular radiosensitivity assays with inherent variability. Radiother Oncol. 1999;50(1):67-75.

46. Safwat A, Bentzen SM, Turesson I, Hendry JH. Deterministic rather than stochastic factors explain most of the variation in the expression of skin telangiectasia after radiotherapy. Int J Radiat Oncol Biol Phys. 2002;52:198-204.

47. Anscher MS, Kong FM, Andrews K. Plasma transforming growth factor $\beta 1$ as a predictor of radiation pneumonitis. Int $J$ Radiat Oncol Biol Phys. 1998;41: 1029-35.

48. Anscher MS, Marks LB, Shafman TD. Using plasma transforming growth factor beta-1 during radiotherapy to select patients for dose escalation. J Clin Oncol. 2001;19:3758-65.

49. Komaki R, Lee JS, Milas L. Effects of amifostine on acute toxicity from concurrent chemotherapy and radiotherapy for inoperable non-small-cell lung cancer: report of a randomized comparative trial. Int J Radiat Oncol Biol Phys. 2004; 58:1369-77.

50. Hendry JH. Biological response modifiers and normal tissue injury after irradiation. Semin Radiat Oncol. 1994;4(2): 123-32.

51. Hopewell JW, Robbins ME, van den Aardweg GJ, Morris GM, Ross GA, Whitehouse E, et al. The modulation of radiation-induced damage to pig skin by essential fatty acids. Br J Cancer. 1993;68(1):1-7.

52. Dorr W, Noack R, Spekl K, Farrell CL. Modification of oral mucositis by keratinocyte growth factor: single radiation exposure. Int J Radiat Biol. 2001;77(3): 341-7.

53. Moulder JE, Robbins ME, Cohen EP, Hopewell JW, Ward WF. Pharmacologic modification of radiation induced late normal tissue injury. Cancer Treat Res. 1998;93:129-51.

54. Stewart F. Retreatment tolerance of normal tissues. In: Steel GG, ed. Basic clinical radiobiology. London: Arnold; 2002. Pp. 231-40.

Manuscript received on 14 December 2004. Revised version accepted on 10 August 2005. 